\title{
Beyond Patchwork Precaution in the Dual-Use Governance of Synthetic Biology
}

\author{
Alexander Kelle
}

Received: 12 December 2011/Accepted: 12 April 2012/Published online: 26 April 2012

(C) Springer Science+Business Media B.V. 2012

\begin{abstract}
The emergence of synthetic biology holds the potential of a major breakthrough in the life sciences by transforming biology into a predictive science. The dual-use characteristics of similar breakthroughs during the twentieth century have led to the application of benignly intended research in e.g. virology, bacteriology and aerobiology in offensive biological weapons programmes. Against this background the article raises the question whether the precautionary governance of synthetic biology can aid in preventing this techno-science witnessing the same fate? In order to address this question, this paper proceeds in four steps: it firstly introduces the emerging techno-science of synthetic biology and presents some of its potential beneficial applications. It secondly analyses contributions to the bioethical discourse on synthetic biology as well as precautionary reasoning and its application to life science research in general and synthetic biology more specifically. The paper then identifies manifestations of a moderate precautionary principle in the emerging synthetic biology dual-use governance discourse. Using a dual-use governance matrix as heuristic device to analyse some of the proposed measures, it concludes that the identified measures can best be described as "patchwork precaution" and that a more systematic approach to construct a web of dual-use precaution for synthetic biology is needed in order to guard more effectively against the field's future misuse for harmful applications.
\end{abstract}

Keywords Synthetic biology · Dual-use - Governance · Precautionary principle $\cdot$ Bioethics

\footnotetext{
A. Kelle $(\bowtie)$

Department of Politics, Languages and International Studies (PoLIS), University of Bath, Claverton Down, 1WN, Bath BA2 7AY, UK

e-mail: a.kelle@bath.ac.uk
} 


\section{Introduction}

Over the past decade synthetic biology has emerged as one of the most dynamic sub-fields of the life sciences. Like most other areas of life science research, such as neurobiology (Royal Society 2012), or converging science and technology, such as nanotechnology (Kosal 2009), synthetic biology has a dual-use potential, i.e. its advances can be used for beneficial purposes as well as for harmful ones. ${ }^{1}$ History teaches that the dual-use potential of major breakthroughs in the life sciences during the twentieth century that were benignly intended, such as in virology, bacteriology and aerobiology, have been applied in offensive biological weapons (BW) programmes (Dando 1999). This pattern of past state practice as well as the more recent concerns about sub-state actors, i.e. terrorist groups, using biological weapons raises the question whether synthetic biology-that could potentially transform biology into a predictive science-is destined to witness the same fate? Over recent years the label 'synthetic biology' has been attached to a number of diverse research and development activities, ranging from the development of 'biobricks' to the search for a minimal cell to the delivery of customized genes by DNA synthesis companies. With a view to the categorical difference between 'standard' and synthetic biology, the US Presidential Commission for the Study of Bioethical Issues has pointed out that:

'Whereas standard biology treats the structure and chemistry of living things as natural phenomena to be understood and explained, synthetic biology treats biochemical processes, molecules and structures as raw materials and tools to be used in novel and potentially useful ways, often quite independent of their natural roles.' (Presidential Commission for the Study of Bioethical Issues 2010: 36; emphasis in original)

The ability to understand, modify, and ultimately create new life forms at the molecular level clearly would represent a scientific paradigm shift with a substantial misuse potential. In general terms, synthetic biology can be misused to engineer biological parts or modules that either increase the efficiency/stability/usability of known biological warfare agents or to synthesize new ones. While currently there are still formidable challenges to overcome e.g. in the creation of synthetic pathogens (Epstein 2008), there is a general acknowledgement that these hurdles will be lowered by scientific and technological advances over the next few years. In the words of a report jointly published by the Massachusetts Institute of Technology (MIT), the Center for Strategic and International Studies (CSIS) and the J Craig Venter Institute, '[i]n the near future, however, the risk of nefarious use will rise because of the increasing speed and capability of the technology and its widening accessibility' (Garfinkel et al. 2007). What is often overlooked in discussions of the "risk" of synthetic biology's dual-use potential being actually misused is the fact that in a strict sense we are no longer dealing with risk. Even though Garfinkel et al. are correct in pointing out that the technological hurdles for misuse will decrease

\footnotetext{
${ }^{1}$ For a recent discussion of the evolution of the dual-use concept and its implications, see van der Bruggen 2011.
} 
over time, the probability of misuse still remains unknown. We are thus dealing with uncertainty, not risk. In addition, determining the malicious effects to which benignly intended synthetic biology advances might be put is problematic, especially if one tries to establish unanticipated consequences of novel biological agents that could be created. Thus, one is dealing with ignorance, not risk (Stirling 2007). It follows that traditional methods of risk assessment are of limited utility in the formulation of dual-use governance measures. Hence, the focus in this article on such proposals and measures that are informed by some form of precautionary reasoning.

Drawing on an increasing body of scholarly work on synthetic biology but also on the governance of this new techno-science from the perspectives of bio-safety, bio-security and bio-ethics, this paper will first provide a brief overview of the emerging field of synthetic biology. This will be followed by a discussion of bioethical and precautionary approaches to life science research in general and synthetic biology in particular. Utilising a dual-use governance matrix as a heuristic device, the final section of the paper will start mapping out governance proposals that follow precautionary reasoning and include an illustrative set of dual-use governance measures that have been proposed or are being pursued by a range of different stakeholders. These are ranging from awareness-raising on the level of individual scientists, to codes of conduct and guidelines, to regulation at the national and international levels. Based on this survey of the field, the paper concludes that the identified patchwork of precautionary measures will need to be systematised and put on a sustainable basis in order to raise the hurdles for the field's future misuse in harmful applications.

\section{The Emergence of Synthetic Biology as a New Techno-Science}

\section{Defining the Field of Synthetic Biology}

As Luis Campos (2009) has shown, scientists' attempts to redesign life have manifested themselves in a number of different approaches throughout the twentieth century. There also seems to be widespread agreement that the term "synthetic biology" entered the scientific vocabulary in 1912 with the publication of the French chemist Stephane Leduc's monograph entitled La biologie synthétique (de Lorenzo and Danchin 2008). Yet, synthetic biology in its current incarnation was initially not destined to carry this label. Instead terms such as 'open source biology' and 'intentional biology' were proposed for the renewed attempt by some to convert biology into a predictive science by incorporating elements of the engineering design cycle. As one early proponent of such a redirection stated, '[w]hen we can successfully predict the behaviour of designed biological systems, then an intentional biology will exist. With an explicit engineering component, intentional biology is the opposite of the current, very nearly random applications of biology as technology.' (Carlson 2001) Besides the Molecular Sciences Institute of the University of California at Berkeley at which Rob Carlson was envisaging a distributed open source biological manufacturing system driving future industry, 
another early institutional hub of contemporary synthetic biology was located at the Massachusetts Institute of Technology (MIT) where Tom Knight started developing the Biobricks standard for biological parts (Knight 2002).

Not surprisingly for a scientific discipline in its formative phase, several competing definitions exist for synthetic biology. One that has received much attention describes synthetic biology as 'the design and construction of new biological parts, devices, and systems, and the re-design of existing, natural biological systems for useful purposes'. 2 This definition clearly reflects the approach to synthetic biology pioneered by scientists at the MIT and emphasizes the concept of standardized biological parts that can be assembled into devices and systems with predefined and predictable functions. Although the MIT framing of the issue area and its support for key activities has been instrumental in triggering the development of the whole field, an exclusive focus on the parts-based approach to synthetic biology tends to overlook other important sub-fields in synthetic biology. Although they cannot all be discussed in detail in this paper, for ease of reference, four different sub-strands of synthetic biology are distinguished here ${ }^{3}$ :

- Engineering DNA based biological circuits, by using standardized biological parts;

- Identifying the minimal genome;

- Constructing protocells, in other words living cells from base chemicals; and

- Creating orthogonal biological systems in the laboratory through chemical synthetic biology.

These four strands are supplemented by two enabling technologies that often are also subsumed under the heading of synthetic biology, although they have a more supportive role to the main strands of the field. This applies first and foremost to the increasingly more affordable large-scale DNA synthesis capabilities that a small number of companies are providing, ${ }^{4}$ but also to the more generic bioinformatics capabilities utilized by those attempting to identify a minimal genome, to model protocells or to apply engineering principles to biology in a more generic sense.

Synthetic biology therefore has to be understood as a key piece in the puzzle of converging science and technology that aims at fusing molecular biology with engineering, by designing and producing new biological parts, devices and systems. To achieve this goal, synthetic biology utilizes high throughput commercial DNA synthesis capabilities to provide the actual biological material for the assembly of genetic circuits. In addition, synthetic biology is relying on increasingly powerful information technology tools that allow for the modelling of certain desired biological functions. A report by the Royal Academy of Engineering (Royal Academy of Engineering (RAE) 2009a) in the UK has described in detail the design cycle that informs the engineering approach to synthetic biology. Standardized bio-

\footnotetext{
2 See: http://syntheticbiology.org/Who_we_are.html accessed at November 62008.

3 This sub-division follows Schmidt (2009); other typologies have been proposed inter alia by O'Malley et al. (2007) and Deplazes (2009).

${ }^{4}$ See for example the webpages of GENEART (www.geneart.com) or Blue Heron (www.blue heronbio.com).
} 
parts that have undergone appropriate quality controls can then in turn be utilized to build standard devices, which, in turn, can be assembled into more complex biological systems.

Several drivers account for the rapid exponential development of the field of synthetic biology over the past few years. These range from dedicated funding initiatives mostly in the US and Europe with the US outspending Europe almost 3 to 1 (Woodrow Wilson International Center for Scholars 2010) to the annual International Genetically Engineered Machines (iGEM) competitions ${ }^{5}$ as well as the five SBx.0 conferences. While three of these conferences were held in the USA (Cambridge, Berkeley and Stanford), SB3.0 took place in Zurich, Switzerland, in 2007 and SB4.0 in Hong Kong in 2008. With SB6.0 taking place in London in summer 2013 the SBx.0 conference series will return back to Europe. Over the course of these international SB-conferences but also national initiatives, such as the UK BBSRC-funded networks in synthetic biology, it has become obvious that synthetic biology encompasses more than only the engineering-inspired parts based approach emphasised here. In this sense some relabeling of more traditional biotechnology and molecular biology approaches can be observed in order to participate in a newly established, 'cool' and potentially well-funded discipline. The foundation for the rapid development of synthetic biology was provided by early optimistic assessments of the potential benefits that could be derived from synthetic biology applications.

\section{Beneficial Uses of Synthetic Biology}

One such assessments of synthetic biology's potential was provided in a 2005 report by an EU high-level expert group, which forecast it to 'drive industry, research, education and employment in the life sciences in a way that might rival the computer industry's development during the 1970s to the 1990s.' (EU 2005) This group of experts envisaged synthetic biology to have such a profound effect by 'reorganizing biotechnological development' in a way so that 'research \& development are likely to proceed in a much faster and much more organized way.' (EU 2005: 13) The report identifies six areas that would benefit from such a streamlining of R\&D processes: biomedicine, synthesis of biopharmaceuticals, sustainable chemical industry, environment and energy, production of smart materials and biomaterials and counter-bioterrorism measures (EU 2005: 13-17).

The most high-profile example for the imminent breakthrough of a ground breaking synthetic biology application is related to the insertion of an engineered metabolic pathway into a yeast strain to produce artemisinic acid (Ro et al. 2006). This in turn can be converted into artemisinin, which forms the basis of antimalarial drugs. The key goal of the attempt to synthesize this artemisinin precursor is to reduce production cost for the therapeutic and thus increase its availability in developing regions of the world. As Chang and Keasling have pointed out in

\footnotetext{
5 Starting out with a handful of mostly undergraduate student teams from US universities in 2004, the 2010 international genetically engineered machines (iGEM) competition has attracted 130 teams from about 20 countries. See http://ung.igem.org/Previous_iGEM_Competitions.
} 
relation to "this approach, the genes related to the biosynthetic pathway for a target natural product are transplanted from the natural host into a genetically tractable host system such as E. coli or S. cerevisiae.' (Chang and Keasling 2006: 1) Similarly, synthetic biologists have made some progress in utilising genetically modified microbes to produce biofuels (Azumi, Hanai and Liao 2008; Keasling and Chou 2008). However, despite being regularly quoted as the most relevant synthetic biology development, it has to be pointed out that the research and development conducted by Keasling and his team are 'light-years' away from the ideal case of a fully modularised process built on standardised bio-parts. Rather, as Keasling himself has acknowledged, his research involves extremely labour intensive trialand error processes that have consumed in excess of ' 150 person-years of work including uncovering genes involved in the pathway and developing or refining parts to control their expression' with the corresponding vast amounts of funding such a process requires (Kwok 2010: 289).

\section{Dual-Use Bioethics and Precautionary Approaches to Risk and Uncertainty in the Life Sciences}

\section{Bioethical Discussion of Synthetic Biology and its Implications}

One of the earliest ethical commentaries on synthetic biology was published already in 1999 in Science and has been regularly quoted by practitioners in the field and academics alike. It acknowledged that in order to

'ensure responsible use of knowledge that could be applied to the construction of biological weapons, we need to give serious thought to monitoring and regulation at the level of national and international public policy.' (Cho et al. 1999: 2089)

Yet, as Yearley has concluded a decade later, while Cho and her colleagues 'highlight things that people may have ethical concerns about, the paper does not set out or determine what the ethical analysis might conclude.' (Yearley 2009: 3) More fundamentally, Yearley's review of bioethics as a template to conduct an ethical review of synthetic biology leads him to caution that such an approach might actually be 'counterproductive since the apparatus constructed to conduct the social and ethical review will come to look like a mere legitimatory cloak for synthetic biology's advance.' (Yearley 2009: 6) Yet, Yearley remains somewhat elusive in specifying what else might serve as a suitable foundation for an ethical review of synthetic biology, either in general terms or with specific reference to the dual-use aspects of the emerging field.

Miller and Selgelid (2007), in contrast, provide a much more detailed and in depth 'ethical and philosophical consideration' of dual-use issues in the life sciences. Although not specifically targeting synthetic biology, their analysis illuminates many aspects of bioethical reasoning that are of relevance to synthetic biology too. Based on 'a particularly morally problematic species of the dual-use dilemma' (Miller and Selgelid 2007:531), in the form of a number of experiments of 
concern, they discuss the permissibility of certain kinds of research, debate dissemination of dual-use research results, and analyse different ethically informed governance models with which to tackle the dual-use issues presented by the biological sciences. With regard to this latter aspect, Miller and Selgelid discard both the laissez-faire option of giving the individual scientist complete autonomy over research with dual-use potential, and the rather draconian option of complete governmental control. Instead they argue for either a mixed system of institutional and governmental controls or a governance approach that would rely on an independent authority being set up (Miller and Selgelid 2007: 573). Thus, while providing a detailed discussion of ethical issues in relation to dual-use life sciences research, and a narrowing down of - in their view - suitable governance options, the analysis remains in this latter dimension somewhat inconclusive.

In contrast to Miller and Selgelid, Ehni's (2008) discussion of the ethical responsibilities of scientists engaged in dual-use research is more limited in scope. He approaches the issue by discussing the 'basic conflict between the freedom of science and the duty to avoid causing harm' from two perspectives, that of 'moral skepticism and the ethics of responsibility by Hans Jonas' (Ehni 2008: 147). On this basis Ehni analyses four basic duties to be considered, ranging from 'stopping research in some cases' to not publishing results and descriptions of research results and possible dual-use applications.' (Ehni 2008: 151) Given the nature of the dualuse issues at hand and the way science is organised, Ehni concludes along the lines of Miller and Selgelid that '[i]t is no solution to the 'dual-use' problem to transfer total responsibility to individuals'(Ehni 2008: 151). Instead he advocates a 'mixed authority' for the governance of dual-use issues, the details of which he also leaves unspecified.

While the recommendation of not assigning sole responsibility to individual scientists is shared by Kuhlau et al. (2008), they point out that the moral duty to prevent harm on the part of an individual researcher does exist and includes both intentional and unintentional harm. Furthermore, such moral duty linked to the professional role of the researcher carries with it a requirement for an 'awareness of relevant regulation and potential dangers' (Kuhlau et al. 2008: 481). This awareness in turn, 'entails a continuous process of reviewing one's work in a wider context.' Based on this reasoning they identify five criteria for the obligation to prevent harm.

'In order to take social responsibility and due care, life scientists should strive to prevent harm that is: Within their professional responsibility... Within their professional capacity and ability... Reasonably foreseeable... Proportionally greater than the benefits... [and] Not more easily achieved by other means...'

(Kuhlau et al. 2008: 481f.)

These criteria are subsequently applied by Kuhlau et al. to a number of proposed obligations for life scientists in relation to dual use issues. They conclude that scientific responsibility 'does not involve preventing the act of misuse but rather involves obligations concerned with preventing foreseeable and highly probable harm.' [Idem: 487, emphasis in original] Such reasonable obligations include in their view the duties to consider negative research implications, to protect sensitive material, technology and knowledge from unauthorised access, and to report 
suspicious activities. While this again represents a useful clarification of the obligation of life scientists including synthetic biologists in relation to dual-use issues they face in their work, it leaves both the institutional and wider governance contexts unexplored within which these duties need to be considered.

The European Group on Ethics in Science and New Technologies to the European Commission (EGE) in its Opinion No 25 on the 'Ethics of synthetic biology' usefully points out in this respect that:

'Governance is an overarching concept including legal, political and ethical considerations. Since synthetic biology may result in major changes of traditional biology, governance needs to be reflected on all these levels, finally entering the legal sphere.' (EGE 2009: 36)

With respect to ethical consideration of synthetic biology, the EGE distinguishes between conceptual and specific issues, and addresses both biosafety and biosecurity under the latter heading (Ibid: 42-44). In its discussion of potential steps to be taken the EGE recommends that:

'ethical issues that arise because of the potential for dual use should be dealt with at the educational level. Fostering individual and institutional responsibility through ethics discussion on synthetic biology is a key issue.' (Ibid: 52)

In addition, the EGE opinion contains three formal recommendations, (1) linking dual-use bio-ethics to the BWC by recommending that this international treaty 'should incorporate provisions on the limitation or prohibition of research in synthetic biology', (2) requesting the European Commission to define a 'comprehensive security and ethics framework for synthetic biology', and (3) requesting the establishment of DNA sequence databases with supporting, legally based rules and procedures. (Idem).

A similarly wide-ranging attempt to chart the ethical issues surrounding synthetic biology has been undertaken by the US Presidential Commission for the Study of Bioethical Issues (PCSBI), which in December 2010 produced its first report entitled New Directions: The Ethics of Synthetic Biology and Emerging Technologies (PCSBI, 2010). Guided by general ethical principles, the report arrives at 18 recommendations, some of which are either informed by the dual use character of synthetic biology or seek to address its implications. Of particular relevance in this context are recommendations 12 and 13. Acknowledging the dynamic character of the field and the resulting changes in dual use issues of relevance the Committee recommends periodic assessments of safety and security risks to be undertaken. It recommends that '[a]n initial review should be completed within 18 months and the results made public to the extent permitted by law.' (Ibid: 13) Should this review identify 'significant unmanaged security or safety concerns', recommendation 13 foresees changes to existing oversight and control mechanisms with a view to 'making compliance with certain oversight or reporting measures mandatory for all researchers ... regardless of funding sources.' (Ibid: 14) This last point would lead to a significant tightening of existing oversight mechanisms as it would expand their 
reach beyond publicly funded life science research and oblige commercial research activities to abide by the same regulatory framework.

The Precautionary Principle and its Application to Dual-Use Life Sciences Research

Emergence of the precautionary principle (PP) is usually traced back to the growing salience of environmental concerns during the 1970s. Since then the PP has been proposed as guidance for action in a variety of contexts and a substantial number of different formulations. Among the most cited versions of the PP are Principle 15 of the 1992 Rio Declaration, according to which ' $[w]$ here there are threats of serious or irreversible damage, lack of full scientific certainty shall not be used as a reason for postponing cost-effective measures to prevent environmental degradation' and the 1998 Wingspread statement. It states that:

'When an activity raises threats of harm to human health or the environment, precautionary measures should be taken even if some cause and effect relationships are not fully established scientifically., 6

However, the PP has been far from uncontroversial. Parke and Bedau (2009) for example discuss eleven criticisms that have been brought forward against the PP in its various forms. Yet, despite these criticisms there have been an increasing number of calls to utilise the PP either as a conceptual tool or in a more pragmatic manner (Stirling 2007, Arcuri 2007). As an example of the latter category Kuhlau et al. (2011) mention the World Medical Association's 2002 declaration on biological weapons, according to which '[a]ll who participate in biomedical research have a moral and ethical obligation to consider the implications of possible malicious use of their findings.' (Kuhlau et al. 2011: 3) In conceptual terms Arcuri usefully introduces a spectrum of versions of the PP, the two extremes of which are 'absence of precaution; and Radical Precaution, that is, to ban any activity that exposes society to uncertain risks irrespective of their potential consequences.' She also maintains that 'the positions of most scholars and most of the endorsements of the principle in legal texts are not to be associated with such extremes.' (Arcuri 2007: 361) In her attempt to further specify this middle ground of precautionary reasoning Arcuri distinguishes between the conditions under which the PP should be applied as well as its substantive and procedural components. As to the element of applicability she proposes to limit the PP to cases involving 'unmeasurable uncertainty' and/or ambiguity and ignorance and summarizes that

'[o]n top of uncertainty, ambiguity and ignorance, most agree that the precautionary principle is to be applied when potential negative outcomes are deemed serious and irreversible.' (Arcuri 2007: 362; emphasis in original)

Paraphrasing her substantive criteria of the PP for the dual-use aspects of synthetic biology, application of the principle should err on the side of preventing misuse. In

\footnotetext{
6 This can be found reproduced in numerous places on the web; see e.g. the Science \& Environmental Health Network webpage at http://www.sehn.org/state.html\#w, last accessed 8 March 2011.
} 
relation to the procedural element of the PP Arcuri emphasises that application of the PP is not a one-off event, and that it is important to consider expert opinion without delegating the decisions to experts, but instead to allow for democratic processes to work themselves out. She therefore concludes that

'the procedural dimension of the principle should favor decision-making processes that are iterative and informative over time and that integrate experts' assessments of the risks to be governed and people's preferences and values.' (Ibid: 364)

Much like Arcuri, Kuhlau and colleagues in their discussion of the PP in relation to dual-use life sciences research also assume 'different degrees of precaution' to be applicable in different circumstances (Kuhlau et al. 2011: 8). In general terms, and after having addressed what they regard as the most serious criticisms of the principle, they conclude that the PP is applicable to dual-use life science research and propose the following version of the principle for this particular issue area:

'When and where serious and credible concern exists that legitimately intended biological material, technology or knowledge in the life sciences pose threats of harm to human health and security, the scientific community is obliged to develop, implement and adhere to precautious measures to meet the concern.' (Idem)

Although this formulation represents a great step forward in arriving at a conceptually sound and at the same time practicable version of the PP for dualuse life science research in general and synthetic biology in particular, it clearly has a few limitations that will need addressing. Although Kuhlau et al. are emphasising the need for flexibility in the PP, it would seem advisable to be more specific in relation to how and by whom it is established that a 'serious and credible threat' exists. Likewise, it could easily appear that they suggest leaving the formulation and implementation of precautious measures exclusively to the scientific community. It would thus seem that the PP put forward by Kuhlau et al. could be usefully expanded by the process element proposed by Arcuri that emphasises repeated engagement and democratic deliberation. It is also worth recalling in this context the above mentioned EGE opinion on synthetic biology and its recognition of ethical, political and legal elements all being of relevance for the governance of the issue area.

\section{Elements of Precaution in the Emerging Synthetic Biology Dual-Use Governance Discourse}

\section{Developing a Dual-Use Governance Matrix for Synthetic Biology}

Although the main focus of synthetic biologists is on the design and engineering aspects of this new field of scientific inquiry, some also emphasize the field's contribution to 'achieving a better understanding of life processes'. (TESSY 2008: 1) Clearly, this better understanding is sought in order to improve the human condition 
via improved diagnostics, therapeutics and other beneficial applications. However, as one study has pointed out, a better understanding of life processes in relation to regulatory systems in the human body also opens new doors for potential misuse of biologically active chemical compounds that can target the human nervous, immune or endocrine systems with a higher degree of specificity (Kelle, Nixdorff and Dando 2006). Given the current state of synthetic biology its misuse potential is still limited and comparable to traditional biotechnological methods. In principle, however, synthetic biology has a much more wide-ranging dual-use potential that will come to fruition once the current problems of standardizing parts and modules has progressed to a point where these are truly compatible and, in addition, can be inserted in a robust chassis for application/dissemination. The fact that this stage has not yet been reached allows for the development and application of precautionary dual-use governance measures in order to minimise the likelihood of nefarious use and to limit its consequences should such misuse occur.

Several such measures have been discussed from an early stage of the development of the field of synthetic biology. However, as will be detailed below, many of them are quite technical in character and address only one aspect of the field, i.e. the screening of DNA-synthesis orders and customers. In order to improve on the proposed measures and to create an overarching framework, a modified version of the 5P dual-use governance matrix proposed by Kelle (2009) will be used in the first instance as a heuristic device for the mapping of individual governance proposals. On the basis of such a mapping exercise it is then possible to analyse the gaps thus identified as to the necessity of additional governance measures being developed. The 5P refer to five policy intervention points-expanding on the three proposed by Garfinkel et al. (2007) — that include the principal investigator (PI), the project, the premise, the provider and purchaser, and the public. While the PI and the public are self-explanatory, the remaining three are aggregate categories that involve different actors and might thus benefit from some further elaboration: intervening at the project level can take a number of forms ranging from the decision to fund a particular project (or not) through to the dissemination of research results at a much later stage. The premise at which research and development activities take place goes beyond the facility in a physical sense and encompasses institutional actors such as research institutions in an academic or commercial environment. Lastly, provider and purchaser of DNA sequences, oligos or corresponding tools and equipment are singled out as their relationships has received much attention in governance proposals so far and is amenable to a specific set of governance measures.

In principle, the dual-use governance measures for synthetic biology range from awareness raising on part of the involved synthetic biologists to education and training of current and future generations of SB practitioners (Minehata et al. 2011), codes of conduct, guidelines, regulation, national laws, and international treaties. The following table maps these measures against the five policy intervention points. It should be noted that the goal of constructing this matrix is not to suggest that all of the resulting fields need to be filled with content. However, utilising the matrix as a heuristic device will facilitate the identification and discussion of dual-use governance proposals that have been put forward or measures that are already 
available and being implemented and investigate these for their precautionary content.

\section{Mapping the Dual-Use Discourse on Synthetic Biology ${ }^{7}$}

One of the earliest proposals to address synthetic biology's dual-use implications that was informed by precautionary reasoning was put forward by George Church. In it he acknowledges that

'While the likelihood of misuse of oligos to gain access to nearly extinct human viruses (e.g. polio) or novel pathogens (like IL4-poxvirus) is small, the consequences loom larger than chemical and nuclear weapons, since biohazards are inexpensive, can spread rapidly world-wide and evolve on their own.' (Church 2004)

In order to address such a low probability-high consequence event, he proposed to develop a system for both 'instrument and reagent licensing', and to screen for select agents, including a 'DNA agent clearinghouse' (Idem). While Church's proposal foresaw some form of government involvement or oversight in both these systems, subsequent proposals placed more emphasis on the self-governance efforts of the scientific community and commercial DNA-synthesis providers.

Such proposals were put forward and discussed at the SB2.0 conference, which took place in Berkeley in May 2006 and during which a full day was devoted to discussion of societal issues related to synthetic biology. The White Paper prepared by Maurer and colleagues for SB2.0 explicitly recognizes that synthetic biology research might be misused to do harm when stating that 'synthetic biologists have an obligation to make sure that their work does not amplify earlier risks or create new ones.' (Maurer, Lucas and Terrell 2006: 2) The subsequently formulated declaration of the conference contains four resolutions that aim at addressing some of the dual-use implications of synthetic biology, in particular DNA synthesis that may give rise to safety or security concerns (Conferees, SB2.0 2006). The focus on DNA synthesis is also reflected in two of the four resolutions contained in the final declaration. In terms of practical next steps to be pursued, the declaration announces the formation of an open working group in support of the improvement of existing software tools for checking DNA sequences, as well as the completion of a study to 'develop policy options that might be used to govern DNA synthesis technology' (Ibid: 3).

This study, which was conducted jointly by the MIT, the J Craig Venter Institute and the Centre for Strategic and International Studies, reinforced the trend to focus dual-use governance options for synthetic biology on DNA synthesis technology. The report's authors identify three policy intervention points: first DNA synthesis itself, as conducted by gene synthesis firms; second, oligonucleotide manufacturers, and; third, DNA synthesizers, as the most effective ones for preventing the misuse of synthetic genomics. For both gene foundries and oligo manufacturers the authors

\footnotetext{
${ }^{7}$ The following discussion of a number of governance proposals and activities is meant to be illustrative rather than exhaustive.
} 
of the report conclude that a combination of screening orders by companies and the certification of orders by a biosafety/biosecurity officer provide the greatest benefits in terms of preventing misuse. The storage of order information by firms was regarded as the most useful tool for responding after an incident had occurred. Lastly, concerning equipment such as DNA synthesizers, the report concluded that the licensing of both equipment and reagents was most likely to enhance biosecurity by preventing misuse (Garfinkel et al. 2007).

Ideas developed in this report were subsequently taken up in proposals for precautionary governance measures by the (then existing) two industry associations in the area of synthetic biology. The first of these groups, the International Consortium for Polynucleotide Synthesis (ICPS) put forward a 'tiered DNA synthesis order screening process.' (Bügl et al. 2007) Based on their concern that the '[m]isuse of DNA-synthesis technology could give rise to both known and unforeseeable threats to our biological safety and security' (Ibid: 627), the ICPS proposal put DNA synthesis companies and their industry association at the centre of a governance structure that would, however, not be a self-contained system of oversight, but rather rely on agreed-upon guidelines. Such guidelines would be operationalized inter alia through lists of 'select agents or sequences' that would determine whether and how to process DNA synthesis orders on the part of those companies that follow the guidelines.

Members of the Industry Association Synthetic Biology (IASB) have focussed on a number of interrelated issues that also revolve around the screening of DNA orders by synthesis companies. These were formulated during an April 2008 workshop on 'Technical solutions for biosecurity in synthetic biology' (IASB 2008). Motivated by 'our responsibility for the scientific field to which we provide services and products' (Ibid: 2), workshop participants agreed on the adoption of five distinct work packages:

1. Harmonization of screening strategies for DNA synthesis orders;

2. Creation of a central virulence factor database;

3. Publication of an article on the status quo of synthetic biology;

4. Establishment of a technical bio-security working group with members from both organisations in order to "discuss improvements and next steps for biosecurity measures", and;

5. Formulation of a code of conduct. (Ibid: 16)

With this last work package, IASB started to move away from technically orientated dual-use governance measures into the political arena of setting standards and promoting best practices.

The focus of proposals described thus far has been on the providers and purchasers of long-strand DNA synthesis, which are located at the bottleneck of the key enabling technology for parts and module based synthetic biology. Some proposals place a higher emphasis on government involvement than others, but all try to minimize the negative impact governance might have on scientific progress and economic benefits. These largely technology and supply-side focussed governance proposals have been supplemented by others, which are also informed 
Table 1 Potential dual-use governance measures at different policy intervention points

\begin{tabular}{llllll}
\hline $\begin{array}{l}\text { Potential dual-use } \\
\text { governance measures }\end{array}$ & \multicolumn{4}{l}{ Policy intervention points } & \\
\cline { 2 - 6 } & $\begin{array}{l}\text { Principal } \\
\text { investigator }\end{array}$ & Project & Premises & Provider/purchaser & Public \\
\hline
\end{tabular}

\section{Awareness raising}

Education/training

Guidelines

Codes of conduct

Regulation

National laws

International treaty/agreement

Source adapted from Kelle 2009

by precautionary reasoning, but involve different fields of the matrix presented above. Two such examples shall be briefly discussed here.

The first is synthetic biology specific and related to two studies undertaken by the Royal Academy of Engineering in the UK on the one hand, and two of the UK's research funding councils, on the other. ${ }^{8}$ Both studies are significant on at least two levels: first, both of them revolve around a public dialogue on synthetic biology, thus aim at expanding the discourse on synthetic biology beyond the expert level. This potentially allows public input into the formulation of governance measures as identified in Table 1 above. Secondly, although not specifically focussing on dualuse questions, some limited coverage of biosecurity issues can still be discerned in the study design. For example agree all participants in the Royal Academy of Engineering study with the statement that 'most scientific research can be used for good or ill' (RAE 2009b: 42), thus accepting that much of synthetic biology is dual use in character. An interesting finding from the research councils' dialogue is related to questions of controls and regulations for synthetic biology. Although no consensus could be achieved among participants concerning the level of regulation or governance measures required, there was a strong opinion emerging that whatever the regulatory efforts, they needed to be coordinated internationally (BBSRC/EPSRC 2010: 44). This indicates the importance of the bottom row of table 1 above.

Another important observation in relation to the two public dialogue exercises is linked to the process dimension of the precautionary principle emphasised by Arcuri and speaks to the goal of embedding the precautionary governance of synthetic biology in some form of iterative, democratically grounded process: although the BBSRC has convened a follow up meeting to take the findings of the public dialogue forward, in essence both of these dialogues have been singular events and there seems to be considerable uncertainty on how to institutionalise public involvement in the synthetic biology governance discourse. However, this is just

\footnotetext{
8 The two research councils in question are the Biotechnology and Biological Sciences Research Council, BBSRC, and the Engineering and Physical Sciences Research Council, EPSRC.
} 
one manifestation of the more generic problem of how to arrive at iterative processes in dealing with the dual-use potential of synthetic biology.

A markedly different approach to dual-use governance in the life sciences in general and with clear applicability to synthetic biology has been taken by a number of different institutions and initiatives that focus on the dual-use education of lifescientists in order to raise their awareness of dual-use issues affecting their work and thus put them in a better position to make informed choices in their research. One initiative by a UK based group of academics has led to the creation of an online Educational Module Resource that is freely available for university-level life science instructors to use in courses on bioethics, biosafety, responsible conduct of science, or as a stand-alone course (Minehata et al. 2011).

A broader initiative along similar lines has been pursued by a committee of the US National Research Council in collaboration with other academies and learned societies. This has resulted in the publication of a report that provides some insight into the state of dual-use education in the life sciences (NRC 2011). As the report points out:

'Available evidence suggests that, to date, there has been very limited introduction of education about dual use issues, either as stand-alone courses or as parts of other courses. Furthermore, few of the established courses appear to incorporate the best practices and lessons learned from research on the "science of learning." (Ibid: 4)

Although the report also mentions recent improvements in the overall dual-use education picture, it is worth remembering that the synthetic biology community is only partially composed of life scientists, and due to its inter-disciplinary nature counts large numbers of engineers and bioinformatics scholars with a grounding in information technology among its ranks. While it may be desirable to address this issue by reference to generic principles of the responsible conduct of science, it would appear that this body of scholarly work has so far ignored dual-use issues. ${ }^{9}$ Adding to this the DIY-biology component of the synthetic biology community, it is fair to assume that the educational dimension of the dual-use governance discourse within the synthetic biology field poses substantial additional challenges to the one encountered in a pure life science context (Edwards and Kelle 2012).

\section{Discussion and Conclusion: Continued Patchwork Precaution or Towards a More Systematic Approach?}

This article set out to discuss the emergence and contours of the new techno-science of synthetic biology with an emphasis on the engineering-orientated parts-based strand of the field. Like much of the life sciences more broadly, synthetic biology

\footnotetext{
9 See for example the US National Research Council's On Being a Scientist for an example of this literature, where dual-use is not addressed (NRC 1995).
} 
research has a clear dual-use potential. In parallel to the development of the technoscience itself, synthetic biology has sparked a number of ethical analyses and governance proposals with a view to ensure its responsible use and to prevent misuse. What is remarkable is the sometimes quite stark gap between broader ethical analyses on the one hand and more practically orientated dual-use governance proposals for synthetic biology on the other. While some in both camps try to bridge the gap, e.g. the work by Miller and Selgelid, or the opinion formulated by the European Group on Ethics, many of these contributions are either covering the life sciences in general and thus do not take into account the peculiarities of synthetic biology, or they deal with synthetic biology specifically, but do focus on more issues than just dual-use.

As the discussion of the precautionary principle has shown, it is indeed possible to formulate a moderate version of the PP that allows developing both substantive and procedural criteria for its application and thus move beyond traditional risk assessments. Research by Kuhlau et al. has shown how a usable baseline formulation of the principle that is applicable to dual-use life science research could look like. As has been argued above, this version of the PP for the life sciences in general and synthetic biology in particular needs further refinement and the integration of a process dimension.

Discussion of some of the more prominent governance proposals for synthetic biology has brought to the fore that quite a few of these at least implicitly contain a precautionary dimension, without this being made explicit or reflected upon conceptually. However, there clearly is a patchwork emerging of governance proposals and initiatives that mostly correspond to the 'provider/purchaser' column in the proposed 5P dual-use governance matrix. These efforts plus educational and public dialogue initiatives could (and should) be integrated into a more systematic precautionary dual-use governance approach for synthetic biology. In order to make progress towards this goal, a structured discourse at institutional, national and international level about the scope, content and processes of such a systematic and sustainable governance approach will be required.

Such a discourse would need to raise awareness of dual-use issues at the individual level through educational measures that go beyond traditional bioethics education, so that synthetic biologists are aware of their responsibility to prevent harm. Ideally this would first happen at undergraduate level, but as both Arcuri and Kuhlau et al. have pointed out, should not be a singular event. Thus, the educational resources that are already available might be usefully complemented by continuous professional development (CPD) activities for those entering the field of synthetic biology from a different disciplinary background. In order to achieve an iterative process of engagement with dual-use issues, such CPD measures should enable and prompt individual researchers to consider precautionary measures at different stages of their research from conceptualisation to publication. However, governance measures aimed at the individual level would need to be embedded into an institutional culture that values the prevention of misuse and harmful applications more highly than is currently the case in many research environments. Such a reorientation would be unlikely to occur on ethical grounds alone, but would in turn have to be embedded in a political discourse about preventing the misuse of 
synthetic biology for nefarious purposes. The above mentioned reports and public dialogues conducted by learned societies and national academies might serve as useful transmission belts for connecting academia with the political world, so that political declarations, such as for example the one issued by the G8 group of states at its 2011 Deauville summit, calling for the more wide-spread adoption of dual-use bio-ethics (G8 2011) can be translated into sustainable governance outcomes.

\section{References}

Arcuri, A. (2007). Reconstructing precaution, deconstructing misconceptions. Ethics \& International Affairs, 21(3), 359-379.

Azumi, S., Hanai, T., \& Liao, J. C. (2008). Non-fermentative pathways for synthesis of branched-chain higher alcohols as biofuels. Nature, 451(3 January 2008), 86-90.

BBSRC/EPSRC. (2010). Synthetic biology dialogue, London, June.

Bügl, Hans., et al. (2007). DNA synthesis and biological security. Nature Biotechnology, 25(6), 627-629.

Campos, Luis. (2009). That was the synthetic biology that was. In M. Schmidt, A. Kelle, A. GanguliMitra, \& H. de Vriend (Eds.), Synthetic biology. The technoscience and its societal consequences (pp. 5-21). Berlin: Springer.

Carlson, R. (2001). Open source biology and its impact on industry. IEEE Spectrum, May, 15-17. Available as Biological Technology in 2050 at www.synthesis.cc/Biol_Tech_2050.pdf.

Chang, M. C. Y. and Keasling, J. D. (2006). Production of isopronoid pharmaceuticals by engineered microbes, Nature Chemical Biology, doi:10.1038/nchembio836.

Cho, M. K., et al. (1999). Ethical considerations in synthesizing a minimal genome. Science, 286(5447), 2087-2090.

Church, G. (2004). A synthetic biohazard non-proliferation proposal, Cambridge, MA: Havard University, available at http://arep.med.harvard.edu/SBP/Church_Biohazard04c.htm.

Conferees, SB2.0. (2006). Public draft of the declaration of the second international meeting on synthetic biology, Berkeley, CA, 30 May, available at http://hdl.handle.net/1721.1/32982.

Dando, M. (1999). The impact of the development of modern biology and medicine on the evolution of offensive biological warfare programmes in the twentieth century. Defense Analysis, 15(1), 43-62.

de Lorenzo, V., \& Danchin, A. (2008). Synthetic biology: Discovering new worlds and new words. EMBO Reports, 9(9), 822-827.

Deplazes, A. (2009). Piecing together a puzzle. An exposition of synthetic biology. EMBO Reports, 10(5), $428-432$.

Edwards, B., \& Kelle, A. (2012). A life scientist, an engineer and a social scientist walk into a lab: Challenges of dual-use engagement and education in synthetic biology. Medicine, Conflict and Survival, 28(1), 5-18.

Ehni, Hans-Jörg. (2008). Dual use and the ethical responsibility of scientists. Archivum Immunologiae et Therapiae Experimentalis, 56, 147-152.

Epstein, G. L. (2008). The challenges of developing synthetic pathogens, Bulletin of the Atomic Scientists, 19 May. Available at: http://www.thebulletin.org/web-edition/features/the-challenges-of-developingsynthetic-pathogens.

European Group on Ethics in Science and New Technologies to the European Commission (EGE). (2009). Ethics of synthetic biology. Opinion No 25, Brussels: European Commission. Available at: http://ec.europa.eu/bepa/european-group-ethics/publications/opinions/index_en.htm.

European Union. (2005). Synthetic biology. Applying engineering to biology, Report of a NEST HighLevel Expert Group, Brussels: European Commission.

G8. (2011). Meeting of foreign ministers, 14-15 March 2011, statement on the 7th review conference for the biological and toxin weapons convention. Available at http://www.canadainternational.gc.ca/g8/ ministerials-ministerielles/2011/g8declarationannex2011-03-15.aspx.

Garfinkel, M. S., Endy, D., Epstein, G. L., Friedmann, R. M. (2007). Synthetic genomics: Options for governance, October. Available at: http://www.jcvi.org/cms/fileadmin/site/research/projects/ synthetic-genomics-report/synthetic-genomics-report.pdf. 
Industry Association Synthetic Biology (IASB). (2008). Report on the workshop "Technical solutions for biosecurity in synthetic biology". Available at http://www.ia-sb.eu.

Keasling, J. D., \& Chou, H. (2008). Metabolic engineering delivers next-generation biofuels. Nature Biotechnology, 26(3), 298-299.

Kelle, A. (2009). Security issues related to synthetic biology. Between threat perception and governance measures. In: Schmidt/Kelle/Ganguli Mitra/de Vriend (Eds.) Synthetic biology. The technoscience and its societal consequences pp. 101-119.

Kelle, A., Nixdorff, K., \& Dando, M. (2006). Controlling biochemical weapons: Adapting multilateral arms control for the 21st century. Basingstoke: Palgrave.

Knight, T. F. (2002). DARPA BioComp plasmid distribution 1.00 of standard biobrick components. Available at http://dspace.mit.edu/handle/1721.1/21167.

Kosal, M. E. (2009). Nanotechnology for chemical and biological defense. New York: Springer.

Kuhlau, F., Erikson, S., Evers, K., \& Höglund, A. T. (2008). Taking due care: Moral obligations in dual use research. Bioethics, 22, 477-487.

Kuhlau, F., Höglund, A. T., Evers, K., \& Eriksson, S. (2011). A precautionary principle for dual use research in the life sciences. Bioethics, 25(1), 1-8.

Kwok, R. (2010). Five hard truths for synthetic biology. Nature, 463(21 January 2010), 289.

Maurer, S. M., Lucas, K. V. and Terrell, S. (2006). From understanding to action: Community-based options for improving safety and security in synthetic biology, UC Berkeley: Goldman School of Public Policy, 15 April. Available at http://citeseerx.ist.psu.edu/viewdoc/download?doi=10.1.1.132. $8678 \&$ rep $=$ rep $1 \&$ type $=$ pdf.

Miller, S., \& Selgelid, M. J. (2007). Ethical and philosophical considerations in the dual-use dilemma in the biological sciences. Science and Engineering Ethics, 13, 523-580.

Minehata, M., et al. (2011). Implementing biosecurity education: Approaches Resources and programmes. Science and Engineering Ethics,. doi:10.1007/s11948-011-9321-z.

National Research Council. (1995). On being a scientist, Washington, D.C.: National Academies Press. Available at http://books.nap.edu/catalog.php?record_id=4917.

National Research Council. (2011). Challenges and opportunities for education about dual use issues in the life sciences. Washington, D.C.: National Academies Press. Available at http://www.nap.edu/ catalog.php?record_id=12958.

O’Malley, M., Powell, A., Davies, J. F., \& Calvert, J. (2007). Knowledge-making distinctions in synthetic biology. BioEssays, 30(1), 57-65.

Parke, E. C., \& Bedau, M. A. (Eds). (2009). The precautionary principle and its critics. In The ethics of protocells. Moral and social implications of creating life in the laboratory (pp. 69-87). Cambridge, MA: MIT Press.

Presidential Commission for the Study of Bioethical Issues. (2010). New directions. The ethics of synthetic biology and emerging technologies, Washington, D.C., December. Available at: http://bioethics.gov/cms/synthetic-biology-report.

Ro, D. -K. et al. (2006). Production of the antimalarial drug precursor artemisinic acid in engineered yeast, Nature 440 (13 April 2006): 940-943. Available at http://www.nature.com/nature/journal/ v440/n7086/abs/nature04640.html.

Royal Academy of Engineering. (2009a). Synthetic biology: scope, applications and implications. London: RAEng.

Royal Academy of Engineering. (2009b). Synthetic biology: public dialogue on synthetic biology. London: RAEng.

Royal Society (2012) Neuroscience, conflict and security. Brain Waves Module 3, London: Royal Society.

Schmidt, M. (2009). Do I understand what I can create? In M. Schmidt, A. Kelle, A. Ganguli-Mitra, \& H. de Vriend (Eds.), Synthetic biology. The technoscience and its societal consequences (pp. 81-100). Berlin: Springer.

Stirling, A. (2007). Risk, precaution and science: towards a more constructive policy debate. EMBO Reports, 8(4), 309-315.

TESSY (2008) TESSY Information leaflet: Synthetic Biology in Europe, available at www.tessy-europe. eu/public-docs/SyntheticBiology_TESSY-Infomation-Leaflet.pdf.

Van der Bruggen, K. (2011). Possibilities, intentions and threats: Dual use in the life sciences reconsidered, science and engineering ethics, doi:10.1007/s11948-011-9266-2. 
Woodrow Wilson International Center for Scholars. (2010). Trends in synthetic biology research funding in the United States and Europe. Synthetic Biology Project Research Brief 1, June. Washington, DC: Woodrow Wilson International Center for Scholars.

Yearley, S. (2009) Review: The ethical landscape: identifying the right way to think about the ethical and societal aspects of synthetic biology research and products, J. R. Soc. Interface, doi:10.1098/ rsif.2009.0055.focus. 